\title{
Risk Assessment and Possible Mitigation Solutions for Using Solar Photovoltaic at Airports
}

\author{
Mahmoud F. Ali, Shady H. E. Abdel Aleem, Member, IEEE, and Ahmed F. Zobaa, Senior Member, \\ IEEE
}

\begin{abstract}
Many airports have become aware of the environmental benefits of using renewable energy resources, and they have focused their efforts on introducing solar photovoltaic (PV) systems on their available free land. Compared to other renewable energy technologies, solar $P V$ arrays are the most suitable technology for airports. Because of the mandatory security requirements at airports, using solar $P V$ is still a complex task because of the possible risks to aviation safety and air transportation systems. Glare due to the reflection of sunlight from the metal parts of a solar PV panel, electromagnetic interference with radar and other navigational aids, wildlife hazards, and the detachment of PV parts are the most common potential risks that could affect aviation safety. In this paper, the emerging safety concerns related to the installation of large-scale PV systems at airports are presented and discussed. Risk assessment matrices with the identification of risks and their potential consequences are demonstrated. In addition, possible mitigation solutions are provided to advance the state of knowledge on this issue. Based on the results gained from the proposed matrices, it is concluded that there is a significant opportunity to use solar PV at airports while complying with the aerodrome boundaries. This can be achieved using special procedures in PV design, installation, and maintenance to overcome the related potential risks.
\end{abstract}

Index Terms-Airports, photovoltaic systems, renewable energy, risk assessment, safety, solar energy.

\section{INTRODUCTION}

$\mathrm{C}$ URRENTLY, global warming, pollution, and fossil fuel shortages have forced all stakeholders to focus more on renewable energy sources such as photovoltaics (PVs), wind energy, and biofuels as environmentally friendly sources of energy. Each energy source has unique requirements and benefits. In addition to their technical benefits, almost all of them have little to no global warming emissions.

Manuscript received March 10, 2016

Mahmoud F. Ali is with the Egyptian Civil Aviation Authority, 11776, Cairo, Egypt (email: M.Fekry@civilaviation.gov.eg).

Shady H. E. Abdel Aleem is with the Mathematical, Physical and Engineering Sciences Department, $15^{\text {th }}$ of May Higher Institute of Engineering, 11731, Helwan, Cairo, Egypt (phone: 002-25161663; fax: 00225519101; e-mail: engyshady(ieee.org).

Ahmed F. Zobaa is with the Collegue of Engineering, Design \& Physical Sciences, Brunel University London, Uxbridge, Middlesex, UB8 3PH, United Kingdom (e-mail: azobaa@ieee.org).
For example, compared to natural gas, which emits between 0.6 and 2 pounds of carbon dioxide equivalent per kilowatt-hour $\left(\mathrm{CO}_{2} \mathrm{E} / \mathrm{kWh}\right)$, wind energy emits between 0.02 to 0.04 pounds of $\mathrm{CO}_{2} \mathrm{E} / \mathrm{kWh}$, and solar PV emits between 0.07 to 0.2 pounds of $\mathrm{CO}_{2} \mathrm{E} / \mathrm{kWh}$ [2]. Hence, they improve the environmental quality and public health. Additionally, renewable energy-based industries are more labor-intensive compared to fossil fuel-based technologies. Accordingly, interest in their use has led to considering using them in new applications such as the power systems of airports [3] and ships [4] in addition to their usage in traditional power systems.

Among all the types of renewable energy sources, solar PV is the only suitable choice for airports. Extensive land areas are available at airports that can provide a safe and protected place for a solar PV plant installation. Based on [5], 7 acres of land can host approximately $1 \mathrm{MW}$ of fixed-axis solar PV; accordingly, there is a potential for $116.7 \mathrm{GW}$ of solar PV arrays on idle land at US airports. An airport principally consists of a runway, which is a restricted area prepared for aircraft landing and taking-off, a taxiway, which is a particular path established for the taxiing of the aircraft so that the plane does not interfere with the operations on the runway, and navigational aids that operate from the control tower. Intuitively, these fundamental parts of an airport must be completely safe and secured [6]. Thus, installing solar PV plants in airports is not an easy task due to the possible adverse impacts that can affect aviation and air traffic system safety. Glare in the eyes of pilots and air traffic controllers, electromagnetic interference with navigational aids, and wildlife and bird strike hazards are the main risks that can cause severe hazards to the aviation system. Moreover, other risks can happen because of any potential event that may occur, such as aircraft accidents or runway excursions. On the other hand, using solar PV at airports will reduce airport operating costs and the greenhouse gases that contribute to climate change [7].

A few years ago, researchers and engineers worked with civil aviation and airports to develop solutions for the problems that may occur, while designing the PV systems to comply with the aerodrome boundaries. It has been introduced that there is a good opportunity to use solar PV at airports with 
special procedures in the $\mathrm{PV}$ designs and installations to reduce the related potential risks [8]-[9]. Consequentially, with the increasing number of airports that plan to be green and intend to use solar PV, the Federal Aviation Administration (FAA) issued guidance for establishing PV installations at US airports in 2010 [5]. Later, it declared that multiple sections will be reviewed based on the experience gained from the applications in this context. In 2013, the FAA published an interim policy for the review of solar energy system projects on Federally Obligated Airports [10]. Until now, these were the only two published guides in this context. In 2015, the FAA issued a technical report on the evaluation of glare as a hazard for general aviation pilots to help airports mitigate risk due to the glare. Additionally, the Solar Glare Hazard Analysis Tool (SGHAT) is used to determine the ocular impact from solar PV on aviation safety [11]. Regarding assessing the possible risks of solar PV at airports, the risk matrix assessment methodology is a suitable method and was recommended by the European Aviation Safety Agency Authority (EASA) [12] and the International Civil Aviation Organization (ICAO) [13]. This methodology is also used by the nuclear industry. Accordingly, in this paper, the matrix based on ICAO is used to assess each potential risk for a solar PV installation at airports and to define its probability, its severity, and possible mitigation solutions. The results indicate that solar PV can be safely installed and operate at airports if suitable solutions are taken into account.

\section{SOLAR PV SYSTEMS AT AIRPORTS}

Airports are now aware that continuous dependence on fossil fuels will not support the global trends towards decreasing $\mathrm{CO}_{2}$ emissions and limiting the average global surface temperature increase to $2{ }^{\circ} \mathrm{C}$ or less, as announced by the United Nations Climate Change Conference that was held in Paris in 2015. Financially, the switch to renewable energies can increase the airport's income from selling energy to other consumers or the network. There are many sources of renewable energy; however, few of them can be used at airports because of airports' particular operating conditions. For example, wind energy is an excellent renewable energy source, but it cannot be used at airports because the heights of the wind towers will penetrate the airport surface [5]. On the other hand, the low profile of solar panels allows for greater flexibility in finding appropriate locations for electricity generation for the airport [5]. Additionally, the broad surfaces provided at airports for both ground mounted and rooftop PVs make the airport an ideal place for large-scale solar PV panel installations. In the past six years, nearly 100 airports worldwide have installed solar PV panels to supply all or part of their electric power demand. The amount of electric power generated from these facilities is $400 \mathrm{MW}$. Fig. 1 shows the placement of these airports [14]. Airports that have solar power installations are concentrated in the northern hemisphere, notably in North America, followed by Europe. Montevideo Airport of Uruguay is the only green airport in South America, Lilongwe Airport of Malawi is the only green airport in Africa, and Dubai World Central Airport is the only green airport in the Middle East region, despite the high potential for using solar energy in this area. Fig. 2 illustrates the distribution of green airports using solar power per region. Cochin International Airport in India was the first airport in the world to cover all of its energy demand from solar PV plants. Its 46,000 panels, stretched across 18 hectares of land, are expected to save over 300,000 tons of $\mathrm{CO}_{2}$ over the next 25 years. The world's largest solar plant at an airport in the future will be at Indianapolis International Airport in the USA. It is planned to have a total capacity of $22.2 \mathrm{MW}$, and it is expected to eliminate 10,000 tons of carbon emissions per year (as a benchmark, this is equivalent to taking 2,000 cars off the road) [14], [15]. In Malaysia, Kuala Lumpur airport is one of the largest green airports in Southeast Asia, producing $19 \mathrm{MW}$ of solar power (4 MW on rooftops, $10 \mathrm{MW}$ on parking canopies and $5 \mathrm{MW}$ on ground-mounted arrays) and eliminating approximately 18,000 tons of $\mathrm{CO}_{2}$ each year. Financially, as announced in [14] and [16], the installed solar power plant saves the airport $\$ 750,000$ annually. In Greece, Athens International Airport produces 13,000 MWh per year, which represents approximately $25 \%$ of the airport's electricity consumption, and eliminates 11,500 tons of emitted $\mathrm{CO}_{2}$ per year. Brisbane Airport in Australia produces 125 MWh and saves 118 tons of $\mathrm{CO}_{2}$ per year [14]. Denver International Airport in the USA has four installation stages of a solar PV farm (DIA-I to DIA-IV), producing $10 \mathrm{MW}$ of electricity, which is equivalent to the power demand of 2,595 typical Denver houses, and eliminating 11,465 tons of $\mathrm{CO}_{2}$ emissions per year [14], [17]. Other airports are using or planning to use solar PV arrays on their land, such as Fresno Yosemite Airport in California, Gatwick Airport in London, Manchester-Boston Regional Airport, Charles de Gaulle Airport in France, and Ancona Falconara Airport in Italy [14], [18].

\section{Risk AsSESSMENT Methodology fOR SOlAR POWER PLANTS AT AIRPORTS}

Risk assessment is a process of evaluating and analyzing a hazard and its consequences through identifying the hazard probability and severity. Risk probability is the likelihood or frequency of occurrence of a defined event that can be a safety effect or an outcome that might occur. It can be classified into five categories: frequent, occasional, remote, improbable, and extremely improbable. Table I demonstrates the meaning and the value of each class according to the ICAO classifications [13]. Risk severity is the extent of harm that might reasonably occur as a consequence or outcome of the hazard. Additionally, risk severity is classified into five categories: catastrophic, hazardous, major, minor, and negligible. 


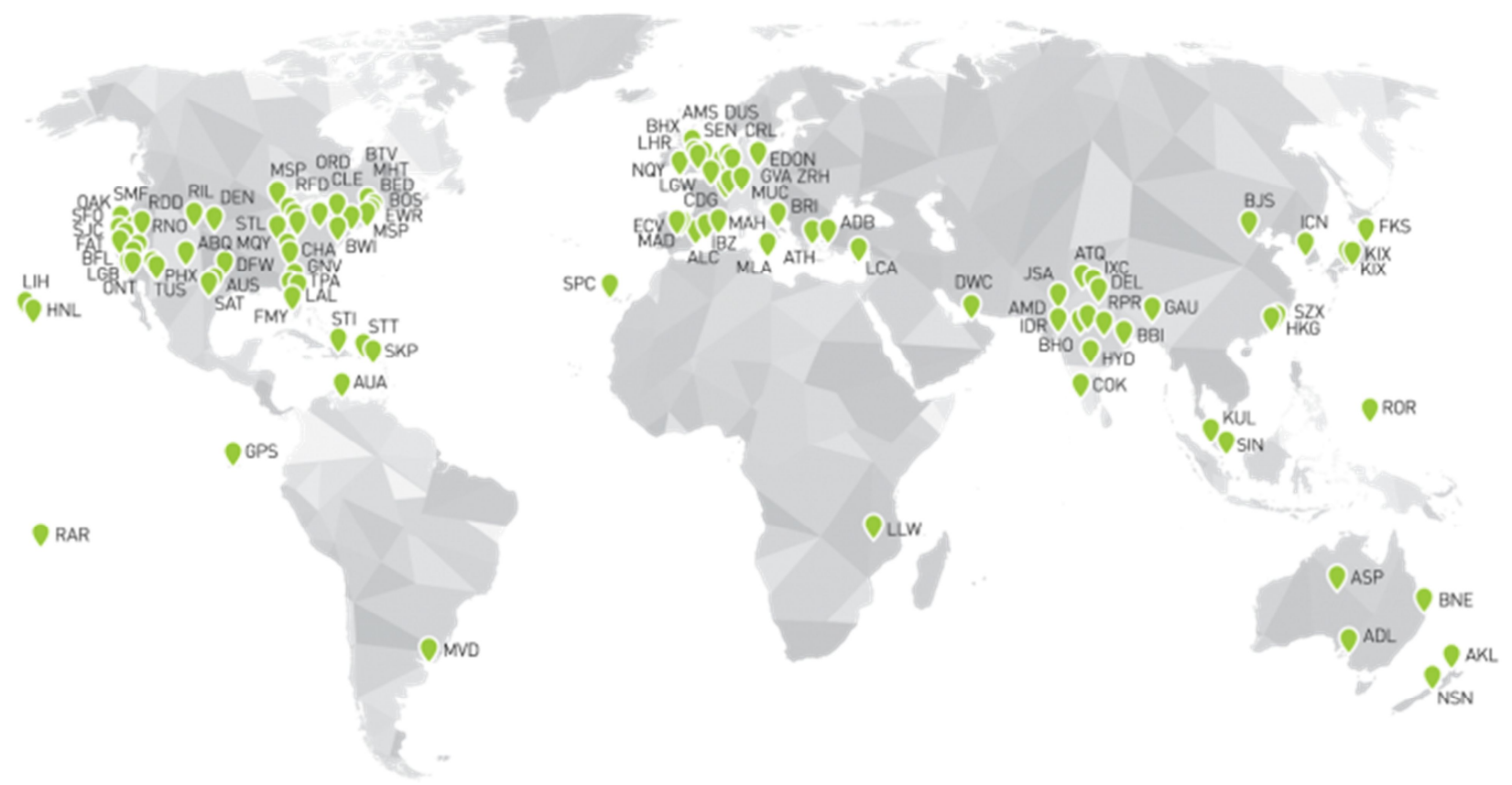

Fig. 1. Airports worldwide that have solar power plants [14].

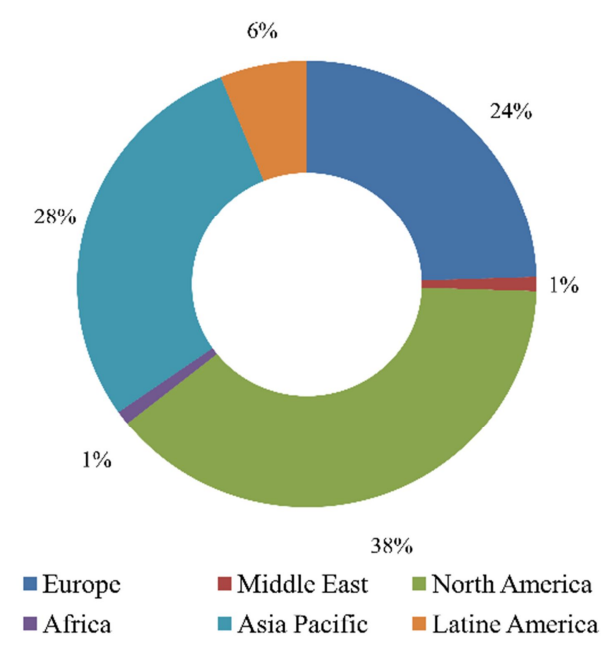

Fig. 2. Distribution of green airports using solar power per region.

TABLE I

RISK PROBABILITY BASED ON [13]

\begin{tabular}{|c|c|c|}
\hline Likelihood & Meaning & Value \\
\hline Frequent & $\begin{array}{l}\text { Likely to occur many times } \\
\text { (has occurred frequently) }\end{array}$ & 5 \\
\hline Occasional & $\begin{array}{l}\text { Likely to occur sometimes } \\
\text { (has occurred infrequently) }\end{array}$ & 4 \\
\hline Remote & $\begin{array}{l}\text { Unlikely to occur but } \\
\text { possible (has occurred rarely) }\end{array}$ & 3 \\
\hline Improbable & $\begin{array}{l}\text { Very unlikely to occur (not } \\
\text { known to have occurred) }\end{array}$ & 2 \\
\hline Extremely Improbable & $\begin{array}{l}\text { Almost inconceivable that } \\
\text { the event will occur }\end{array}$ & 1 \\
\hline
\end{tabular}

Risk severity is considered the main contributor that can reasonably determine a risk index. Table II demonstrates the meaning and the value of the risk severity classes [13]. The risk index (RI) consists of an alphanumeric designator (for example, " $5 \mathrm{~A}$ ") that indicates the combined results of the probability and severity assessments. Accordingly, the risk assessment matrix is given in Table III.

TABLE II

RISK SEVERITY BASED ON [13]

\begin{tabular}{|c|c|c|}
\hline Severity & Consequences & Letter \\
\hline Catastrophic & $\begin{array}{l}\text {-Equipment destroyed } \\
\text {-Multiple deaths }\end{array}$ & A \\
\hline Hazardous & $\begin{array}{l}\text {-A large reduction in safety margins, } \\
\text { physical distress or a workload such that } \\
\text { the operators cannot be relied upon to } \\
\text { perform their tasks accurately or } \\
\text { completely } \\
\text {-Serious injury } \\
\text {-Major equipment damage }\end{array}$ & B \\
\hline Major & $\begin{array}{l}\text {-A significant reduction in safety } \\
\text { margins, a decrease in the ability of the } \\
\text { operators to cope with adverse operating } \\
\text { conditions as a result of an increase in } \\
\text { workload or as a result of conditions } \\
\text { impairing their efficiency } \\
\text {-Serious incident } \\
\text {-Injury to persons }\end{array}$ & $\mathrm{C}$ \\
\hline Minor & $\begin{array}{l}\text {-Nuisance } \\
\text {-Operating limitations } \\
\text {-Use of emergency procedures } \\
\text {-Minor incident }\end{array}$ & $\mathrm{D}$ \\
\hline Negligible & -Few consequences & $\mathrm{E}$ \\
\hline
\end{tabular}


After formulating the risk assessment matrix, the risk tolerability can be determined to clarify the different regions, whether intolerable, tolerable or acceptable, combined with their corresponding risk indices, as demonstrated in Table IV. A red color indicates an intolerable (unacceptable) region; the yellow color indicates a tolerable (fair or improvable) one, and the green color indicates an acceptable area, as shown in Tables III and IV.

Other methodologies for risk assessment are found in the literature such as the butterfly nick risk assessment method and bow-tie diagrams [9], [19], [20]. However, the presented methodology is recommended by the EASA [12] and the ICAO [13]. Accordingly, it is used to assess any hazard or risk in airports or related air transportation systems.

\section{RESULTS AND DISCUSSION}

From the studies and the literature, we have identified five main hazards that need to be analyzed to accurately determine their severity. These hazards are glint and glare, electromagnetic interference, wildlife and bird hazards, detachment of PV parts, and potential events.

In the following, each risk will be presented and discussed. The possible mitigation solutions will be highlighted. It should be mentioned that the suggested solutions are based on previous studies in this context, offline questionnaires, pilots' reports, and the viewpoints of engineers in various countries who work with civil aviation and airports to find PV solutions for aerodromes.

TABLE III

ICAO RISK ASSESSMENT MATRIX

\begin{tabular}{|c|c|c|c|c|c|c|}
\hline \multirow{2}{*}{\multicolumn{2}{|c|}{$\begin{array}{l}\text { Risk } \\
\text { probabilities } \\
\text { and their values }\end{array}$}} & \multicolumn{5}{|c|}{ Risk Severity } \\
\hline & & $\begin{array}{c}\text { Catastrophic } \\
\text { A }\end{array}$ & $\begin{array}{c}\text { Hazardous } \\
\text { B }\end{array}$ & $\begin{array}{c}\text { Major } \\
\mathrm{C}\end{array}$ & $\begin{array}{l}\text { Minor } \\
\text { D }\end{array}$ & $\underset{\text { E }}{\text { Negligible }}$ \\
\hline Frequent & 5 & $5 \mathrm{~A}$ & $5 \mathrm{~B}$ & $5 \mathrm{C}$ & $5 \mathrm{D}$ & $5 \mathrm{E}$ \\
\hline Occasional & 4 & $4 \mathrm{~A}$ & $4 \mathrm{~B}$ & $4 \mathrm{C}$ & $4 \mathrm{D}$ & $4 \mathrm{E}$ \\
\hline Remote & 3 & $3 \mathrm{~A}$ & $3 \mathrm{~B}$ & $3 \mathrm{C}$ & $3 \mathrm{D}$ & $3 \mathrm{E}$ \\
\hline Improbable & 2 & $2 \mathrm{~A}$ & $2 \mathrm{~B}$ & $2 \mathrm{C}$ & $2 \mathrm{D}$ & $2 \mathrm{E}$ \\
\hline $\begin{array}{l}\text { Extremely } \\
\text { Improbable } \\
\end{array}$ & 1 & $1 \mathrm{~A}$ & 1B & $1 \mathrm{C}$ & $1 \mathrm{D}$ & $1 \mathrm{E}$ \\
\hline
\end{tabular}

TABLE IV

RISK TOLERABILITY

\begin{tabular}{|c|c|c|}
\hline Region & Assessed indices & Criterion \\
\hline Intolerable region & $5 \mathrm{~A}, 5 \mathrm{~B}, 5 \mathrm{C}, 4 \mathrm{~A}, 4 \mathrm{~B}, 3 \mathrm{~A}$ & $\begin{array}{l}\text { Unacceptable under the } \\
\text { existing circumstances }\end{array}$ \\
\hline Tolerable region & $\begin{array}{l}5 \mathrm{D}, 5 \mathrm{E}, 4 \mathrm{D}, 4 \mathrm{E}, 4 \mathrm{C}, 3 \mathrm{~B}, \\
3 \mathrm{C}, 3 \mathrm{D}, 2 \mathrm{~A}, 2 \mathrm{~B}, 2 \mathrm{C}, 1 \mathrm{~A}\end{array}$ & $\begin{array}{l}\text { Acceptance based on risk } \\
\text { mitigation }\end{array}$ \\
\hline Acceptable region & $\begin{array}{l}3 \mathrm{E}, 2 \mathrm{D}, 2 \mathrm{E}, 1 \mathrm{~B}, 1 \mathrm{C}, 1 \mathrm{D}, \\
1 \mathrm{E}\end{array}$ & Acceptable \\
\hline
\end{tabular}

\section{A. Glint and Glare Risk: Consequences and Mitigation} Solutions

By definition, glint is a momentary flash of light, while glare is a continuous source of bright light. These hazards are the most common hazards of solar PV plants at airports. According to the FAA draft [5] and the FAA interim policy [10], an installation of solar PV at an airport can threaten the aviation, the cockpit of an aircraft, and the air transportation safety as the glare will likely decrease visibility for the pilots, thereby making it harder to control the aircraft. Usually, pilots describe glare as "blinding" in their reports when flying near a solar electric system [11], [21], [22]. Air traffic controllers (ATCs) at the Manchester-Boston Regional Airport reported significant problems due to glare reflecting from the solar panels towards the tower. The FAA [5] stated that the glare from direct sunlight would occur tens of times per year, and the Aviation Safety Reporting System (ASRS) database recorded that at least one pilot reported glare as a hazard. With glare, pilots cannot see if there is air traffic nearby as the glare is similar to looking into the sun [11], [23]. Moreover, the FAA made the "Solar Glare Hazard Analysis Tool" (SGHAT) for airports planning to install solar PV arrays to help them to determine whether such installations would endanger aviation safety. Assessing this risk using the ICAO risk assessment matrix, it would be classified as a hazard with a probability class that has a value equal to 5 because it can frequently occur (more than one time per year). Additionally, the severity is considered as major (Class C) because a serious incident that can cause injury to persons will occur if a pilot misses the approach due to glints or glares. Thus, the risk index of this hazard is designated as $5 \mathrm{C}$. Based on Table IV, the tolerability of this hazard is unacceptable under the existing circumstances. The possible mitigation solutions and preventive measures for this hazard are summarized below.

1) The first action is to use the FAA tool (SGHAT) to analyze the glare. Based on the experimental work carried by [20] in French airports, it was found that a reflecting luminance of less than $20.000 \mathrm{~cd} / \mathrm{m}^{2}$ would be acceptable. This luminance number is quite low and would be equal to the sun reflection on a page of white paper.

2) Panels should be installed away from any final threshold approach and landing paths.

3) Panels should be constructed of dark, light-absorbing materials.

4) Panels should be covered with an antireflective coating [24].

5) Panel surfaces should be roughened as much as possible. This makes the reflected light bounce back onto the surface, thus reducing the reflection [25].

6) Blinds should be added to the control tower.

7) The units should be rotated away from the stowaway position after sunset to limit potential inadvertent glares.

8) Finally, if needed, flight operations should be restricted during periods when glare is expected to impact lowflying aircraft [26].

Applying these preventative measures, the probability of glare becomes extremely improbable, and its severity will be 
minor. Accordingly, the corresponding risk index will be 1D, and the tolerability will change to the acceptable region.

\section{B. Electromagnetic Interference Risk: Consequences and Mitigation Solutions}

Electromagnetic interference (EMI) is a major aviation problem that can arise from solar PV installations reflecting radar signals. This may lead to the loss of radar coverage or the production of false signals. Moreover, these physical structures can obstruct the view of navigational aids. In general, airport navigational aids such as radar, instrument landing system (ILS), microwave landing system (MLS), VHF omnidirectional range navigation system (VOR), and distance marker equipment (DME) are sensitive and critical markers that aid air traffic controllers and pilots in navigation. Any interference with their signals can cause significant problems [27], [28]. Basically, the expected EMI due to solar PV can be produced by the metal components of PV modules, tracking systems, cables, or inverters that include high-speed switching semiconductor circuits that produce electromagnetic radiation at the switching frequency in addition to the harmonic distortion [29], [30].

Numerous case studies have indicated that the EMI from the PV installations is a low-risk hazard. The expected emissions from the PV arrays (that have filtered inverters) comply with the Federal Communications Commission, CFR 47, Rule 15 (10-1-95 Edition) [31] for limiting radio frequency (RF) emissions. For unfiltered inverters, the inverter switching frequency is low compared to the RF frequencies, as the inverter switching frequencies are on the order of tens of $\mathrm{kHz}$, and there is no expected interference above $1 \mathrm{MHz}$ (at least, they are insignificant above the background RF) [32]- [34].

Assessing this risk using the ICAO risk assessment matrix, it would be classified as a hazard with a probability class that has a value equal to 4. This is because EMI occasionally occurs ( 1 to 0.1 per year). Additionally, the severity is considered hazardous (Class B) because it can cause serious injury and significant equipment damage. Thus, the risk index of this hazard will be designated as 4B. Based on Table IV, the tolerability of this hazard is unacceptable under the existing circumstances. The possible mitigation solutions and preventive measures for this hazard are given below.

1) Grant the PV system EM compatibility using shielded frames.

2) Use shielded or twisted cables.

3) Protect and filter electronic equipment such as inverters.

4) Introduce a separation distance of 250-500 feet between the PV units and the existing navigational aids to minimize the physical blocking or reflection of the radar signals.

Applying these preventative measures, the probability of EMI becomes improbable, and its severity will be major. Accordingly, the corresponding risk index will be $2 \mathrm{C}$, and the tolerability will change to the tolerable region.
C. Wildlife and Bird Strike Risk: Consequences and Mitigation Solutions

In most cases, it is unachievable to completely eliminate the natural animal risk, especially if the airport is near a lake. Wildlife and bird strikes are critical aviation hazards. The existing FAA guidance does not address the wildlife impact or mitigation strategies. Detailed data on the consequences of using solar PV on wildlife is quite lacking; however, the effects of this hazard are assumed to be negative [35].

PV panels are considered an attraction for animals (rabbits, dogs, and cats) and birds, especially during the birds' annual migration, for perching or shading. Recently, some researchers studied the bird use of PV arrays in three states in the USA [36] and clearly demonstrated that PV arrays did not increase the bird hazards to aviation at airports. Assessing this risk using the ICAO risk assessment matrix, it would be classified as a hazard with a probability class that has a value equal to 4 . Additionally, the severity is considered as hazardous (Class B) because any collision between birds and aircraft engines can cause severe injuries and equipment damage. Thus, the risk index of this hazard is designated as $4 \mathrm{~B}$, the same as the EMI hazard. Based on Table IV, the region of tolerability is unacceptable under the existing circumstances. The possible mitigation solutions and preventive measures for this hazard are given below.

1) The PV system should include built-in protections to avoid local animal development.

2) Bird noise emissions and laser lights should be used.

3) Ultimately, the undesirable solution of hunting can be practiced if needed [37].

Applying these mitigation solutions, the probability of this hazard becomes improbable. However, its severity will be hazardous because of the number of aircraft and animal/bird collisions. Accordingly, the corresponding risk index will be $2 \mathrm{~B}$, and the tolerability will change to the tolerable or the improvable region.

\section{Detachment of PV Parts Risk: Consequences and Mitigation Solutions}

The existence of foreign object debris (FOD) on a runway is a high risk that can cause a major aircraft accident. No one has forgotten the Concord aircraft fall in Paris due to FOD [38]. Solar PV can be a source of FOD as its parts can separate from their structures due to many reasons, such as strong winds, hurricanes, earthquakes, vibrations, incorrect combinations of attachments and maintenance activities. Loose PV parts, when separated from their structures, can reach the runway or the taxiway and cause damage to the aircraft body, especially after take-off. Assessing this risk using the risk assessment matrix; this hazard is classified as remote hazardous with a probability class that has a value equal to 3 . Additionally, the severity is considered as catastrophic (Class A) because it can destroy equipment and cause multiple deaths. Thus, the risk index of this hazard is designated as 3A. Based on Table IV, the tolerability of this hazard is unacceptable under the existing circumstances (intolerable region). The possible mitigation solutions for this hazard are given below. 
1) Secure the PV module by sealing the parts well.

2) Regularly examine the attachments.

3) Perform protective maintenance for the PV modules.

4) Use barriers or fences to keep loose parts away from the runway under the detachment case.

Applying these mitigation solutions, the probability of this hazard becomes extremely improbable. However, its severity will still be catastrophic. Accordingly, the corresponding risk index will be $1 \mathrm{~A}$, and the tolerability will change to the improvable region.

\section{E. Potential Events Risk: Consequences and Mitigation Solutions}

Different potential events may occur in the presence of solar PV at airports, which can impact aviation safety, such as an aircraft running towards a solar PV plant, colliding with PV modules and stopping there. Hence, this risk is considered catastrophic due to its related consequences on passengers' lives, aircraft and aviation safety. An aircraft running towards a PV farm can cause aircraft damage due to the heavy ground stopping the aircraft and causing jet fuel leakage. Additionally, the broken modules and electrical cables can produce sparks and fire that will damage the plane and endanger human lives. Additionally, an aircraft that stops within a solar PV farm is considered an obstacle to the passengers' exit and rescue equipment's entry. Moreover, a toboggan should not hurt the PV structures when spreading out. Finally, the rescue team must be able to intervene on the plane and extract the passengers. Accordingly, using the risk assessment matrix, the probability is improbable, which equals 2 , and the severity is catastrophic (A). Thus, the risk index is $2 \mathrm{~A}$, which is the tolerable region. However, more actions should be taken into consideration for mitigating this hazard.

Two types of mitigation solutions are possible: mechanical mitigation and electrical mitigation. Both are given below.

\section{A. Mechanical Mitigation Solutions}

1) PV modules that have frangible couplings should be used.

2) Lightweight PV systems should be used.

3) Broken glass should not blow apart (like car glass).

4) PV systems, even broken, should be smooth and keep the parts together to minimize the possibility of hurting the toboggans or the passengers.

5) Physical dispositions would allow a group of people to run away from the aircraft through corridors.

6) An appropriate crash gate should be used that allows rescue vehicles to reach the aircraft.

\section{B. Electrical Mitigation Solutions}

1) A type of electrical frangibility to the system should be practiced.

2) A PV system with a protection circuit should be used to force the system to have zero current-zero voltage under abnormal events.

3) The PV electrical system should be controlled to quickly halt its operation when a PV panel is disconnected in case of unusual incidents.

Applying both the mechanical and electrical mitigation solutions, the probability of this hazard becomes extremely improbable. Its severity will be major. Accordingly, the corresponding risk index will be $1 \mathrm{C}$, and the tolerability will change to the acceptable region.

\section{F. Summary}

Table $\mathrm{V}$ gives the complete risk assessment matrix of the studied hazards of using solar PV at airports before and after applying the suggested mitigation solutions.

TABLE V

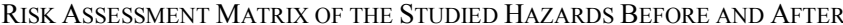
APPLYING THE SUGGESTED MITIGATION SOLUTIONS

\begin{tabular}{|c|c|c|c|c|c|c|}
\hline \multirow{2}{*}{\multicolumn{2}{|c|}{$\begin{array}{l}\text { Risk } \\
\text { probabilities } \\
\text { and their values }\end{array}$}} & \multicolumn{5}{|c|}{ Risk Severity ${ }^{\mathrm{a}, \mathrm{b}}$} \\
\hline & & Catastrophic & Hazardous & Major & Minor & Negligible \\
\hline Frequent & 5 & & & I & & \\
\hline Occasional & 4 & IV & II and III & & & \\
\hline Remote & 3 & & & & & \\
\hline Improbable & 2 & V & [III] & [II] & & \\
\hline $\begin{array}{l}\text { Extremely } \\
\text { Improbable }\end{array}$ & 1 & [IV] & & [V] & [I] & \\
\hline
\end{tabular}

${ }^{\text {a}}$ Hazards under study: $\mathrm{I}=$ glare reflection, $\mathrm{II}=\mathrm{EMI}, \mathrm{III}=$ wildlife and bird strikes, IV = PV parts detachment, and V = potential events.

${ }^{\mathrm{b}}$ The square brackets represent the risk assessment after applying the mitigation solutions.

In general, frequent failures in a solar PV project are not usually encountered because of poor practice in a particular step but are a combination of improper actions in different stages. Commonly, inadequate communication between the designers and installers is the primary reason [39]. In addition, using unqualified and inexperienced labor is the secondary cause as it dramatically worsens the situation. Therefore, installers, designers, and workers should understand the airport requirements and that airports are not primarily designated for solar PV activities. Finally, there is a large opportunity to use solar PV systems at airports if the various mitigation solutions are taken into account as a framework for the design, installation, and maintenance of solar PV systems at airports.

\section{CONCLUSION}

Solar PV arrays are the most suitable renewable energy technology that matches airports. Because of the mandatory security requirements at airports, using solar PV at airports is still one of the most complex tasks because of the possible risks to aviation safety and the air transportation system. In this paper, the main hazards that can occur and affect aviation safety, such as glare reflection, electromagnetic interference with navigational aids, wildlife hazards, PV parts detachment, and other potential events, are intensely discussed. Hazard identification and risk classification are clarified based on the European Aviation Safety Agency Authority (EASA) and 
International Civil Aviation Organization (ICAO) risk assessment matrices while identifying the consequences and the possible mitigation solutions. Based on the results gained from the proposed matrices, it is concluded that there is a significant opportunity to use solar PV at airports while complying with the aerodrome boundaries. This can be achieved by using special procedures in the PV designs and installations to reduce the related potential risks. Finally, a detailed framework for the design, installation, and maintenance of solar PV systems at airports is needed to guide the researchers and engineers working in green airports. Moreover, developing new standards for energy efficiency in airports to comply with the green power requirements for these sensitive applications is an emerging necessity.

\section{ACKNOWLEDGMENT}

The authors gratefully acknowledge and thank the team of International Setec in France, the Egyptian Airports Company, the Egyptian Civil Aviation Authority, and the Air Transport Action Group (ATAG) in Switzerland for their support, helpful comments, and data and information they freely provided during the preparation of this study.

\section{REFERENCES}

[1] Z. Salameh, Renewable energy system design, UK, Academic Press, Elsevier Inc., 2014.

[2] IPCC Special Report on Renewable Energy Sources and Climate Change Mitigation. Working Group III of the Intergovernmental Panel on Climate Change, 2011.

[3] A. Kellas, "Utilizing the solar energy for power generation in Cyprus," 8th Mediterranean Conference on Power Generation, Transmission, Distribution and Energy Conversion (MEDPOWER 2012), Cagliari, 2012, pp. 1-7.

[4] H. Lan, S. Wen, Y. Hong, D. C. Yu, L. Zhang, "Optimal sizing of hybrid PV/diesel/battery in ship power system," Applied Energy, vol. 158, pp. 26-34, Nov. 2015.

[5] Federal Aviation Administration (FAA). Technical guidance for evaluating selected solar technologies on airports. Report FAA-ARPTR-10-1, Washington, DC, USA, 2010.

[6] International Civil Aviation Organization (ICAO) Annex 14 Aerodromes Volume I “Aerodrome Design and Operation” 6th Ed., July 2013.

[7] S. H. E. Abdel Aleem, A. F. Zobaa, H. M. Abdel Mageed, "Assessment of energy credits for the enhancement of the Egyptian Green Pyramid Rating System," Energy Policy, vol. 87, pp. 407-416, Dec. 2015.

[8] S. B. Barrett, and P. M. DeVita, Investigating safety impacts of energy technologies on airports and aviation. Airport Cooperative Research Program Synthesis 28. Washington, DC, USA: Transportation Research Board of the National Academies, 2011.

[9] J.-Luc Wybo, "Large-scale photovoltaic systems in airports areas: safety concerns," Renewable and Sustainable Energy Reviews, vol. 21, pp. 402-410, May 2013.

[10] Interim Policy: FAA Review of Solar Energy System Projects on Federally Obligated Airports. Oct. 23, 2013.

[11] J. A. Rogers, C. K. Ho, A. Mead, A. Millan, M. Beben, and G. Drechsler, "Evaluation of Glare as a Hazard for General Aviation Pilots on Final Approach," July 2015.

[12] European Aviation Safety Agency Authority, Organization and operations requirements for aerodromes. Document NPA 2011-20 (A), 2011.

[13] International Civil Aviation Organization (ICAO). Doc. 9859 "Safety Management Manual (SMM)," 3rd Ed. 2013.

[14] Air Transport Action Group (ATAG). "Aviation Climate Solutions,", Sept. 2015.

[15] IND Solar Farm. Indianapolis International Airport, 2015. [Online]. Available: http://indsolarfarm.com/the-solar-farm/
[16] J. F. SunEdison, "Solar energy for airports," Environmental Workshop. ICAO HQ, Montreal, Canada, 2014. [Online]. Available: http://www.icao.int/Meetings/EnvironmentalWorkshops/Documents/201 4-GreenTechnology/6_Frank_Sunedison.pdf

[17] Denver International Airport (DIA), Energy management: Solar arrays, 2015. [Online]. Available: http://www.flydenver.com/about/administration/energy_management

[18] A. Kandt, and R. Romero, "Siting Solar Photovoltaics at Airports," National Renewable Energy Laboratory, NREL/CP-7A40-62304, 2014.

[19] R.M. Arnaldo-Valdes, F. G. Comendador, L.M. Gordun, F. J. SaezNieto, "The development of probabilistic models to estimate accident risk (due to runway overrun and landing overshoot) applicable to the design and construction of runway safety areas," Safety Science, vol. 49, pp. 633-650, 2011.

[20] International Setec. [Online]. Available: http://www.inter.setec.fr

[21] C.K. Ho, C.A. Sims, J.M. Christian, "Evaluation of Glare at the Ivanpah Solar Electric Generating System," Energy Procedia, vol. 69, pp. 12961305, May 2015.

[22] R. C. Lee, J. Douglas, J. Wallens, "Pilot Complaints of Visual Impacts from Ivanpah Solar Electric Generating System," Las Vegas, McCarran International Airport, March 2014.

[23] The Aviation Safety Reporting System (ASRS), 2013. [Online]. Available: http://asrs.arc.nasa.gov/search/database.html

[24] Anti-Reflection Coatings. PV Education.org. [Online]. Available: http://www.pveducation.org/pvcdrom/design/anti-reflection-coatings

[25] Surface Texturing PV Education.org. [Online]. Available: http://pveducation.org/pvcdrom/design/surface-texturing

[26] Airport Cooperative Research Program (ACRP) Synthesis 28. Investigating Safety Impacts of Energy Technologies on airports and aviation, 2011.

[27] D.K.Y. Wong, D.E. Pitfield, R.E. Caves, A.J. Appleyard, "The development of a more risk-sensitive and flexible airport safety area strategy: Part I. The development of an improved accident frequency model," Safety Science, vol. 47, pp. 03-12, 2009.

[28] D.K.Y. Wong, D.E. Pitfield, R.E. Caves, A.J. Appleyard, "The development of a more risk-sensitive and flexible airport safety area strategy: Part II. Accident location analysis and airport risk assessment case studies," Safety Science, vol. 47, pp. 913-924, 2009.

[29] S.H.E. Abdel Aleem, M.E. Balci, A.F. Zobaa, and S. Sakr, "Optimal Passive Filter Design for Effective Utilization of Cables and Transformers under Non-sinusoidal Conditions," Proc. 16th Int. Conf. Harmonics and Quality of Power, ICHQP'14, Bucharest, Romania, May 25-28, pp. 626-630, 2014.

[30] A.F. Zobaa, and S.H.E. Abdel Aleem, "A New Approach for Harmonic Distortion Minimization in Power Systems Supplying Nonlinear Loads," IEEE Transactions on Industrial Informatics, vol. 10, no. 2, pp. 14011412, May 2014.

[31] R. Bonn, "FCC Part 15 Rules and PV Systems," Sandia Technical Note, SAND97-1043, 1997.

[32] R. Araneo, S. Lammens, M. Grossi and S. Bertone, "EMC Issues in High-Power Grid-Connected Photovoltaic Plants," in IEEE Transactions on Electromagnetic Compatibility, vol. 51, no. 3, pp. 639-648, Aug. 2009.

[33] M. C. Di Piazza, C. Serporta, G. Tine and G. Vitale, "Electromagnetic compatibility characterisation of the DC side in a low power photovoltaic plant," 2004 IEEE International Conference on Industrial Technology, IEEE ICIT '04, Hammamet, Tunisia, Dec. 8-10, pp. 672677, 2004.

[34] C. Deline, "Renewable Energy, Photovoltaic Systems Near Airfields: Electromagnetic Interference," CONTRACT REPORT CR-NAVFACEXWC-PW-1504, National Renewable Energy Laboratory (NREL), April 2015.

[35] A. Kandt and R. Romero, "Implementing Solar Technologies at Airports, " National Renewable Energy Laboratory (NERL), NREL/TP7A40-62349, July 2014.

[36] T. L. DeVault, T. W. Seamans, J. A. Schmidt, J. L. Belant, B. F. Blackwell, N. Mooers, L. A. Tyson, L. Van Pelt, "Bird use of solar photovoltaic installations at US airports: Implications for aviation safety, "Landscape and Urban Planning, vol. 122, pp. 122-128, Feb. 2014.

[37] J. L. Belant, and J. A. Martin, "Bird harassment, repellent, and deterrent techniques for use on and near airports, "Airport Cooperative Research Program Synthesis. Washington, DC, USA: Transportation Research Board of the National Academies, 2011.

[38] 2000: Concorde crash kills 113, BBC home: On This Day, 2000. [Online]. 
http://news.bbc.co.uk/onthisday/hi/dates/stories/july/25/newsid_2797000 2797965.stm

[39] PVTRIN, Definition of installers' professional framework and development of the training methodology: Catalogue of common failures and improper practices on PV installations and maintenance. IEE/09/928/SI2.558379, 2011. 